\title{
AC 2010-2373: RESEARCH EXPERIENCES FOR UNDERGRADUATES IN MICROMANUFACTURING
}

Wayne Hung, Texas A\&M University

Jorge Leon, Texas A\&M University

Luis San Andres, Texas A\&M Univeristy 


\title{
Research Experiences for Undergraduates in Micromanufacturing
}

\begin{abstract}
Texas A\&M University provides research experiences to undergraduate students for micro turbomachinery development. The NSF-sponsored summer program allows undergraduate students, selected from a large pool of students nationwide, to work closely with TAMU investigators and graduate students on topics related to the design and manufacturing of micro turbomachinery. Some students study materials, dynamics, or thermal aspects of turbomachinery, while others explore and develop various micromanufacturing technologies for microturbine fabrication. The nature of micromachinery requires the development of novel micromanufacturing technologies for superalloys and other robust engineering materials. The selected participants study micromilling, electrical discharge micromachining, electrochemical micromachining, and vacuum assisted microcasting. They complete a research methodology workshop and then apply to their own projects through setting objectives, planning schedule, performing experiments, documenting data, presenting results at the campus-wide poster session, and then publishing on national conference proceedings. The program also allows balanced time between technical projects and group activities. The participants tour other research facilities, visit relevant industries, and complete a series of seminars on research and graduate school preparation.
\end{abstract}

Students are carefully selected from an applicant pool with special attention to those from underrepresented groups and coming from schools with limited research facilities. About 33\% of participants are female; they are among the $57 \%$ of underrepresented group in this program. At the end of the 2009 summer program the participants successfully designed and fabricated the first prototype of micro turbomachinery. They overwhelmingly enjoyed the program and majority of the participants would like to continue their research careers at graduate schools.

\section{Introduction}

Gas-driven turbomachinery has been developed to either generate or recover energy in power plants or advanced transporting vehicles. However conventional turbomachines are too large and heavy for a host of new applications in military, homeland security, transportation, aerospace, and other commercial applications. To address these needs, research is being conducted to develop novel micro turbomachinery systems that are small, lightweight, fuel efficient, and portable. The interdisciplinary areas of research in which students can participate include dynamics, mechanics, microfluidics, electronics, thermal science, material science, optimization techniques, and advanced micromanufacturing.

Texas A\&M University aims to develop micro turbomachinery and has completed the three-year NSF-sponsored Research Experiences for Undergraduates (REU) program. This paper presents the program, its structure, activities, and results. 


\section{Program Objectives}

The educational and technical objectives of our program are:

Educational objectives:

1) To provide participants with hands-on research experiences. Participants will be exposed to different technical aspects yet interrelated fields to cultivate a productive research culture.

2) To provide participants with hard skills for technical innovation. Participants will explore a new technical field in such a way to stimulate further study.

3) To prepare students with soft skills for successful researching. Participants will work with others to develop a productive teamwork attitude and improve their communication skills.

4) To motivate participants for research career. Participants will be given information about graduate schools and expose to research environment in industry.

5) To promote diversity. Participants will be selected in such a way to enhance diversity and maximize the program impact.

6) To continue improvement. Participants will provide continuous feedback to improve current and future program.

7) To complement other institutions. This program provides research experiences to undergraduate students from other institutions that lack research facilities.

\section{Technical objectives:}

1) To design and construct novel air bearing (foil and metal mesh), conduct measurements of bearing structural coefficients, perform rotordynamic tests to determine the bearings' reliability, and perform computational simulations of nonlinear foil bearing dynamic forced performance.

2) To develop suitable techniques to fabricate microparts for micro turbomachinery. These include high speed micromilling in micromist lubrication, high-frequency electrochemical micromachining, electrical discharge micromachining, laser microwelding, and vacuum assisted microcasting.

3) To improve current testing system and design a new test rig for much smaller micro turbomachinery. To quantify parameters of novel foil gas bearing and prepare them for high temperature testing.

\section{Results}

Thirty students participated in this program over the last three years. The student list, their home institutions, and their works are documented in the program website (http://reumicro.tamu.edu).

\section{Program Structure:}

The program was announced via NSF website, several mass mailing lists, and presentations at different institutions by the PI and co-PI when possible. Prospective candidates then applied directly after viewing the program website that detailed activities, responsibilities, project description, schedule, and benefits. Upon collecting applications and recommendation letters, the PI and hosting faculty screened, phone interviewed, and then selected suitable participants according to their interests, the research needs, and NSF guidelines. The program provided training to ten students every summer for three consecutive years. To maximize the program impact, new students were selected each summer since no repeating was allowed. 
A typical summer program would last ten weeks and majority of participants were from other institutions as suggested by NSF. The selected participants worked with their faculty advisors to develop individual research objectives and then paired with graduate students to work on different research projects. By doing so, the participants would gain valuable research experiences in the field of their choices, while the graduate students would have extra hands to complete their research works. Pre and post program surveys for each specific program and for all REU programs at TAMU not only gave the PIs a valuable tool to improve their programs, but also to measure each program success for giving undergraduate students the experiences of performing cutting edge research.

\section{Educational Achievement:}

The diverse group of 30 students is selected from universities and colleges nationwide. There are 22 participants $(73.3 \%$ ) from other institutions: ten female, seven from underrepresented groups, and one profound deaf person (Fig. 1). The participants worked closely with TAMU investigators and graduate students, attend a GRE preparation class, tour various labs/company/research centers (Fig. 2), and participate in weekly seminars with different topics like research methodology, ethics, going to graduate school, etc. The participants learned to plan their research activities, weigh alternatives, execute the tasks, document their work, and then present the results as posters at the end of the program. In addition to gaining the technical hardskills, the participants also practiced other soft-skills during the training: ethical commitment, effective teamwork, project management, and presentation skill.

Post program surveys indicate that $88 \%$ of participants would recommend the program to their friends, and $94 \%$ think the program provided a good learning environment and research experiences to undergraduate students. The overwhelming majority of the participants $(90 \%)$ indicated their strong intention to attend graduate school or to choose research as their career option. Eight participants (27\%) have actually admitted to graduate schools so far (Fig. 1).

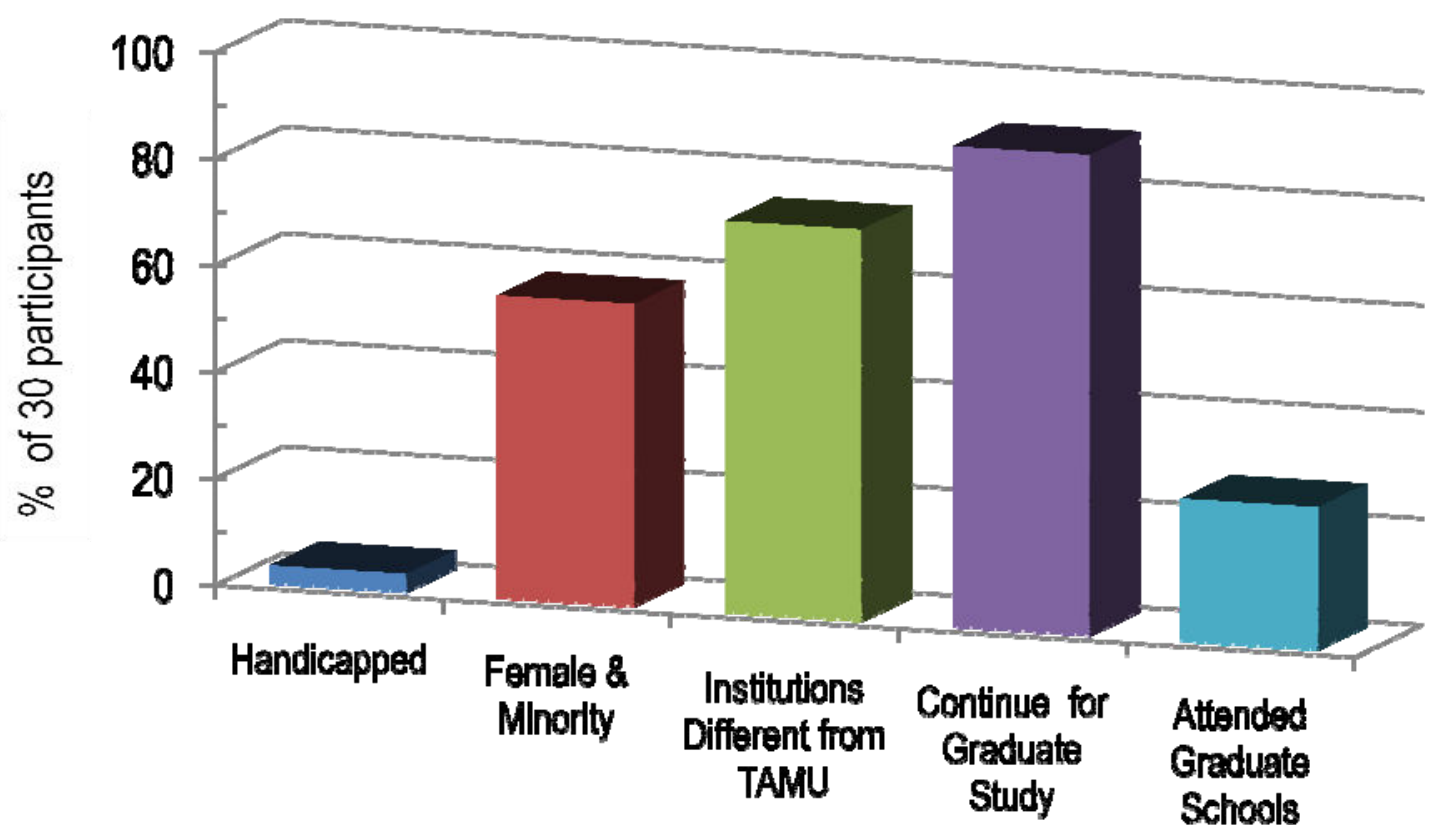

Fig. 1: Profile of participants 
Technical Achievement:

The contribution to mechanical/manufacturing engineering knowledge was two-fold: (i) design of novel miniature gas bearing to support high speed rotating machinery, and (ii) development of manufacturing techniques to fabricate components of micro turbomachinery. The first microturbine was successfully designed and fabricated by the participants (Fig. 3). The following selected results were contributed by the participants and pairing graduate students for the last three summers.
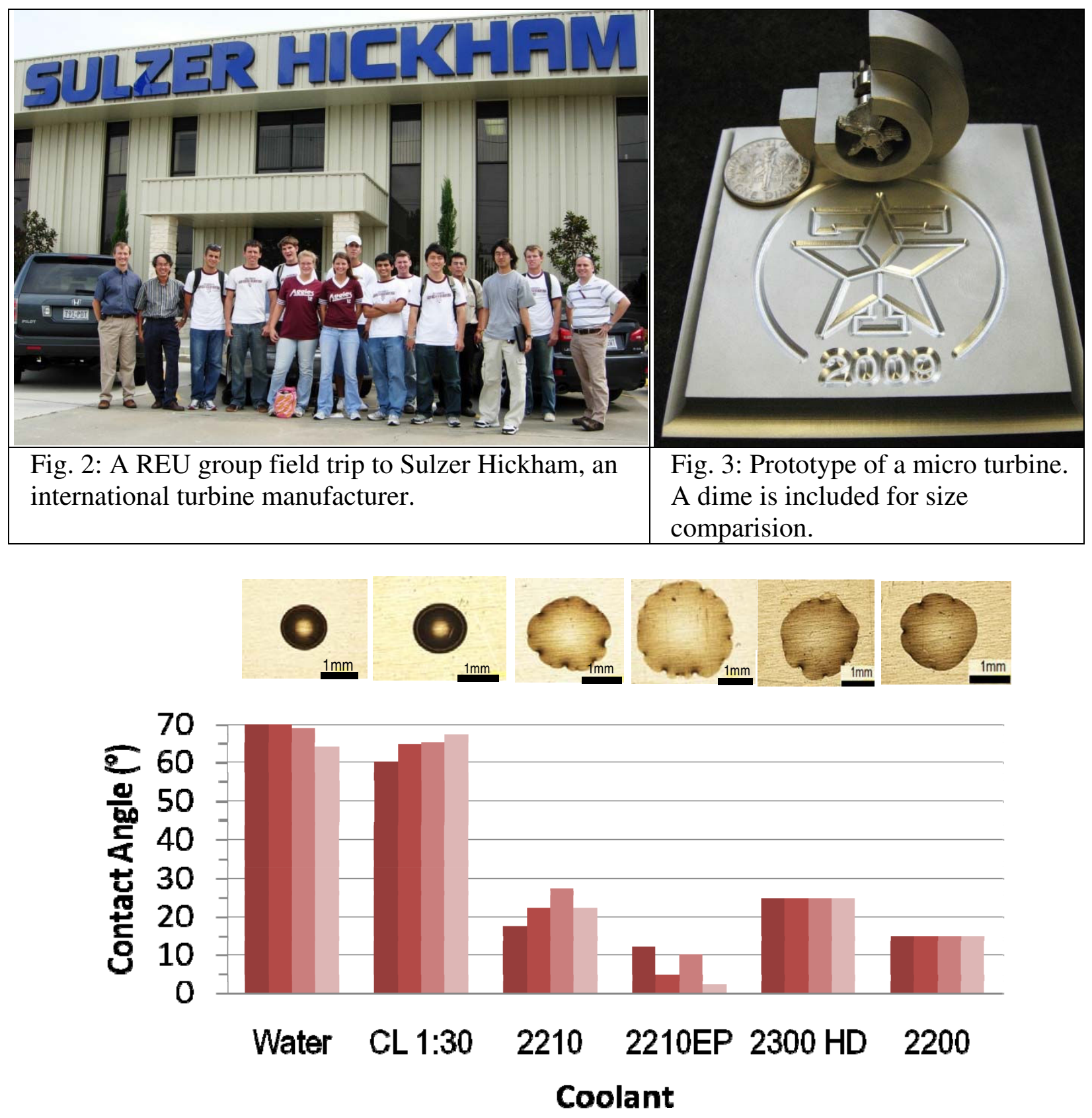

Fig. 4: Measured contact angles of different coolants on 316L stainless steel. Constant volume $0.25 \mu \mathrm{L}$ of coolants on flat sheets ${ }^{4}$. 


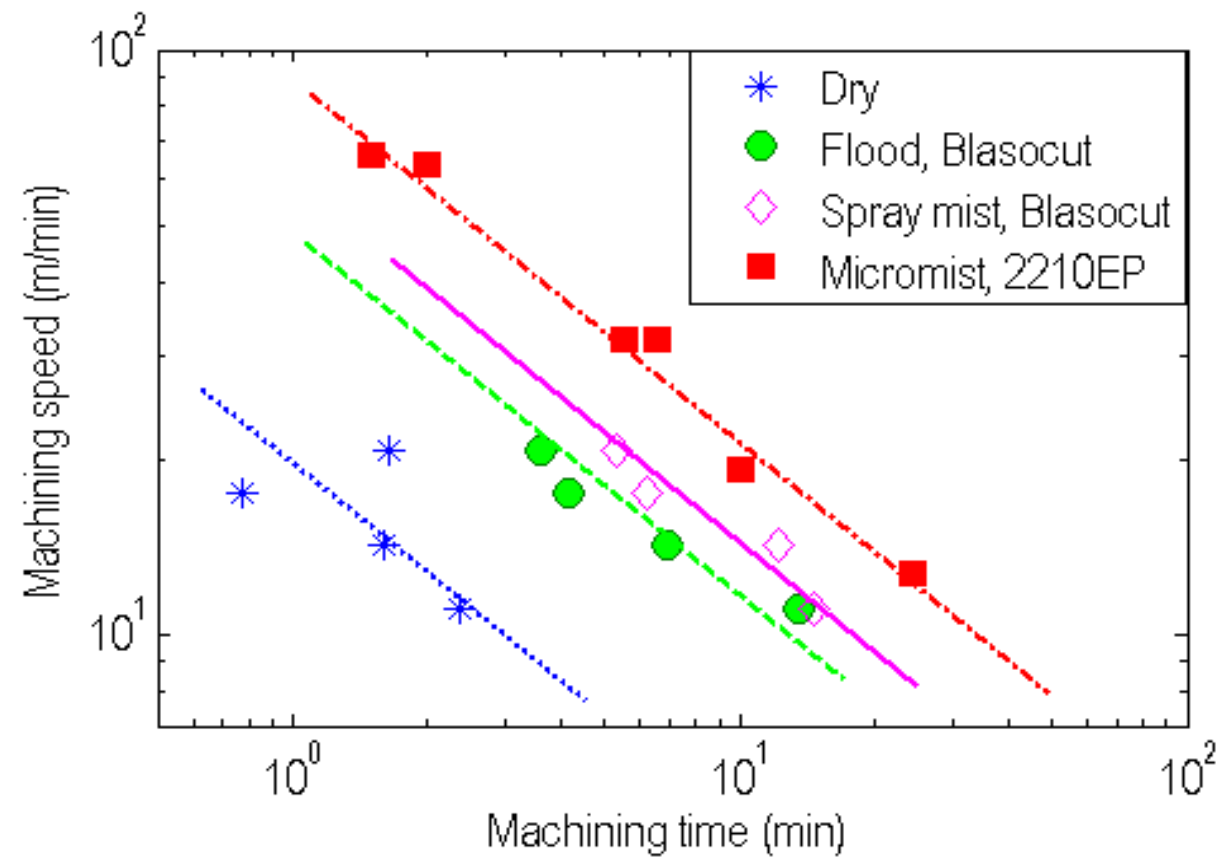

Fig. 5: Micromilling of 316L stainless steel and effect of cutting fluids. Cutting tool with 2 flutes, $8^{\circ}$ back rake, $30^{\circ}$ helix, $\varnothing 1.016 \mathrm{~mm}(0.040 \mathrm{in})$, uncoated WC. Chipload $10 \mu \mathrm{m} /$ tooth (0.0004 in/tooth), $0.35 \mathrm{~mm}(0.014$ in) axial depth, $0.56 \mathrm{~mm}$ (0.022 in) radial depth, climb (down) side milling ${ }^{1}$.

In one of the projects the students developed novel air bearings. A bearing is a low friction mechanical component that supports rotating systems. A conventional rolling-contact bearing uses balls or pins to reduce friction while keeping the rotor in place. Such bearing requires copious lubrication and only perform satisfactorily at low speeds. Micro turbomachinery uses smaller rotors at much higher speeds, well above 100,000 rpm. Novel oil-free gas bearings must be developed to replace rolling-contact bearings. Feasibility of gas bearings can be obtained with simulation and experimental data from prototypes. Vibration and shock responses of the rotor can be effectively controlled with optimal design and pressure control ${ }^{7,8}$.

In another project the students contributed to manufacturing science. In a micromilling study, data from computational fluid dynamics show motions of microdroplets in the neighborhood of a rapidly rotating cutting tool. The microdroplets not only penetrate the boundary layer but also wetted the tool surface for machining and cooling enhancement. Contact angle measurement data suggested the proper wetting of workpiece material (Fig. 4) and cutting tools occurs when a low surface energy cutting fluid is used. A significant gain in tool life suggests the effectiveness of micromist in micromachining (Fig. 5) ${ }^{2,4}$. Another project involved the fabrication of microfeatures (smaller than human hair size) on hard superalloys for turbomachinery. A microtool would break easily due to high cyclic cutting force and spindle runout. Finite element analysis and experimental studies helped to define thresholds beyond which a microcutting tool would fail catastrophically ${ }^{1}$. 
Two non-traditional techniques were also studied; namely, electrical discharge micromachining $(\mu \mathrm{EDM})$ and electrochemical micromachining $(\mu \mathrm{ECM})$. These are promising technologies for manufacturing of micro turbomachinery components since these processes work independently of material strength and hardness. In the former process, the optimized parameters were established to provide the best surface finish on stainless steel surface. This process, however, is limited due to gradual wear of the electrodes. The latter process is the main focus of the research since it can produce consistent profiles without electrode wear.

In the $\mu \mathrm{ECM}$ process, a high frequency current, in megahertz range, is particularly useful since it can produce a sharper machined profile but at the expense of lower material removal rate $(\mathrm{MRR})^{3}$. A compromised approach would be to rough a workpiece at low frequency and high current density and then finish the work at high frequency and low current density (Fig. 6) ${ }^{5,6}$. Metallographic study indicates no subsurface damage of workpiece material after being removed by $\mu \mathrm{ECM}$. Another application for $\mu \mathrm{ECM}$ is deburring or polishing of microcomponents. Rough surfaces on a microcomponent can be quickly and effectively polished after moving a suitable electrode above the surface at optimal conditions (Figs. 7a and 7b). Both $\mu \mathrm{EDM}$ and $\mu \mathrm{ECM}$ processes are limited to conductive materials, which are commonly used for turbomachinery ${ }^{9,10}$.

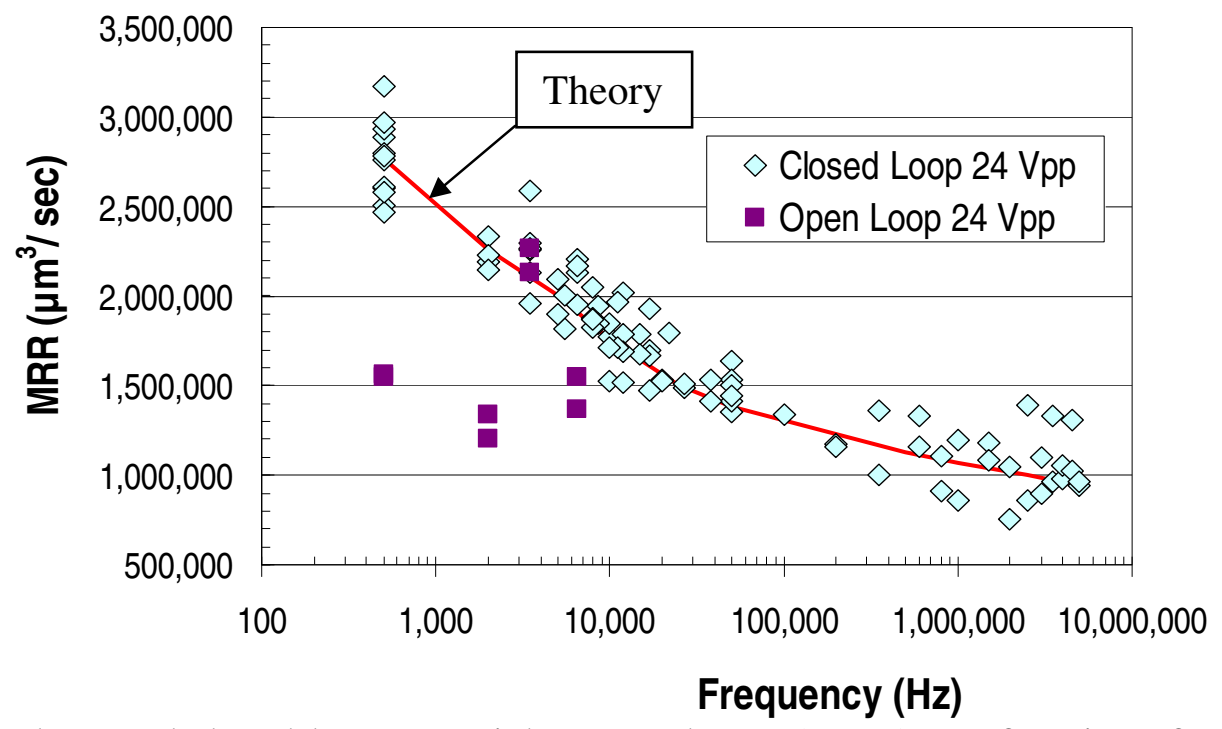

Fig. 6: Open-loop and closed-loop Material Removal Rate (MRR) as a function of pulse frequency. 316L stainless steel, $3 \% \mathrm{NaNO}_{3}, 16-24 \mathrm{~V}_{\mathrm{pp}}$ pulse ${ }^{9}$.

Laser microwelding of aluminum graphite composites was also studied. A laser beam rapidly heats the composite to above its melting temperature. The large mass of surrounding composite then cools the weld quickly. Such high temperature and fast cooling rate of a weld degenerates the graphite fibers to form brittle aluminum carbides (Fig. 8a). The problem is fixed by using a lower melting temperature aluminum-zinc alloy as filler for brazing. Metallographic examination shows no aluminum carbide is observed in the brazed composites (Fig. 8b).

Complex shapes such as the impeller in a micro turbomachinery pose a significant engineering challenge to design and manufacture. An impeller is first designed on a computer, and then a life-size plastic model is made with a rapid prototyping system. A mold is then produced to 
produce metallic impeller using vacuum assisted investment casting process. The metal impeller is shown with the first prototype microturbine in Fig. 3.

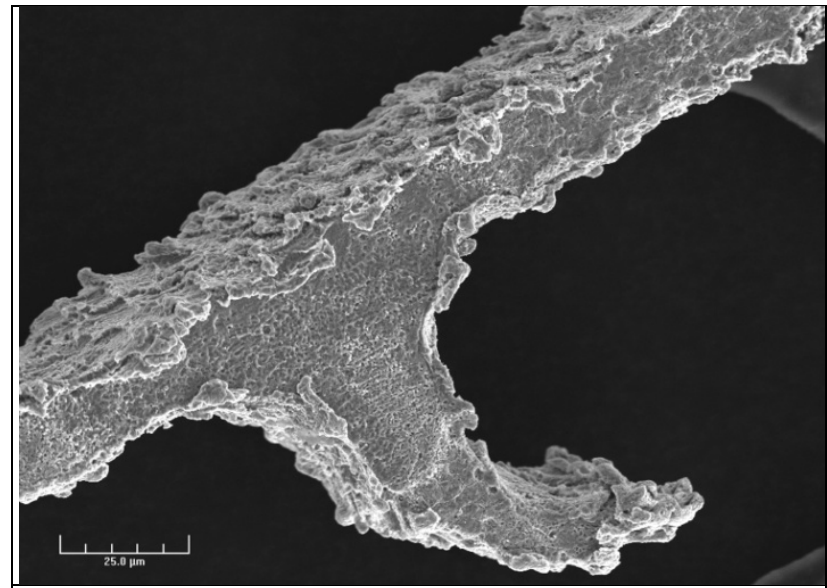

Fig. 7a: A microcomponent with rough surfaces after $\mu$ EDM.

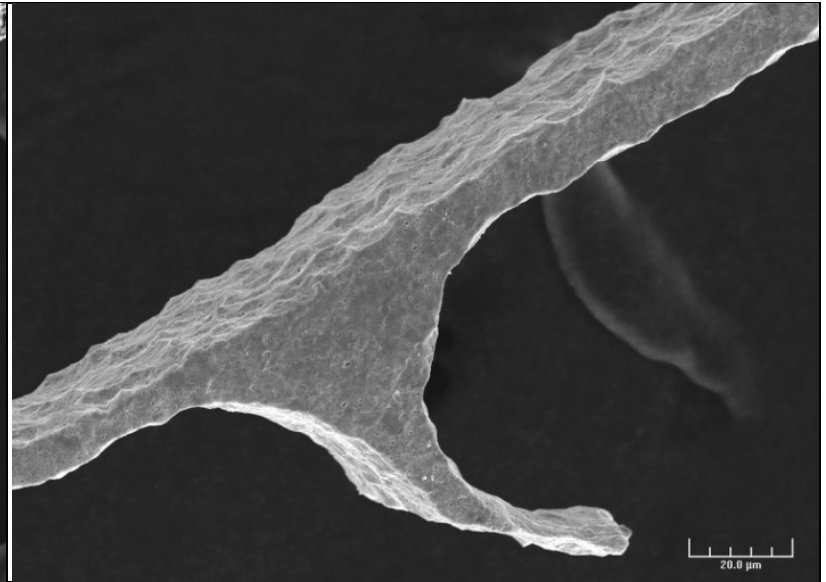

Fig. 7b: The burr-free microcomponent after $\mu \mathrm{ECM}$.

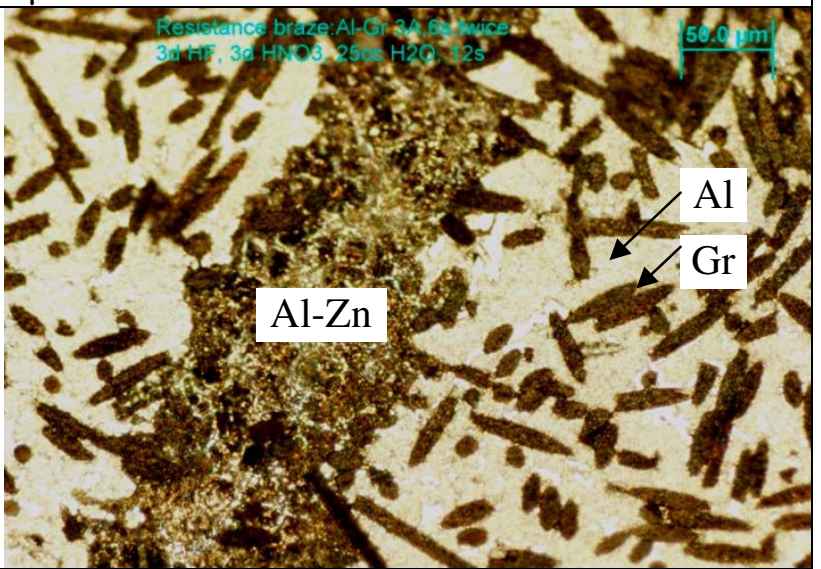

Fig. 8b: Successful joining of aluminum graphite composites with aluminum-zinc brazing alloy.

\section{Broader Impact}

Mutual benefits are achieved through the close interaction among TAMU graduate students and the undergraduate participants. The graduate students sharpen their soft-skills in team leadership, organization, and communication though interaction with the participants. On the other hand, the undergraduate participants learn all research aspects when assisting the graduate students in designing and fabricating test components, performing experiments, compiling and analyzing data, documenting studies, and presenting results.

The results of the research are disseminated beyond the immediate team. At the end of each summer program, all participants prepare concise posters and share their findings with others interdisciplinary researchers on campus. The activity, coordinating by the Office of Vice President for Research, has attracted an average of $\sim 80$ posters each summer from all research programs at TAMU. 
The project also provided additional physical resources and funding for research and education. The partner organizations (Haas, Unist, MA Ford, and Agilent) donated equipment to use beyond summer REU projects. The equipment have been used for research and teaching for three other classes to benefit approximately 150 students each year. Funding and other equipment are also received from Turbomachinery Consortium, Honeywell Turbo Technology, and NASA Glenn Research Center for our Turbomachinery Lab at TAMU. Additional funding is also provided by Mexican organizations such as Conacyt, Cideteq, and Comimsa for parallel international educational and research projects.

Results of our REU projects are posted on the project's websites (http://reumicro.tamu.edu, and http://rotorlab.tamu.edu/TRIBGroup). These websites also benefits the scientific and engineering communities by showing technical findings from all participants. Selected studies are presented at different technical and educational conferences. Our university offers tours to high school and community college students every semester. The visitors are divided into smaller groups to tour different departments, laboratories, and research centers according to their interest. We take the opportunity to show the visitors our laboratories, posters, and highlight of the findings by REU students. This outreach activity not only informing young students about the program, but also encourages them to study engineering/technology and engages in research.

\section{Summary}

The project "REU: Development of Micro Turbomachinery" was successfully completed. We achieved our educational objectives by cultivating the life-long research skills to thirty undergraduate students while achieving our technical objective upon development of a microturbine. The seed funding from National Science Foundation was followed with additional funding and equipment donation from industry and other organizations.

\section{Acknowledgement}

This material is based upon work supplied by the National Science Foundation under grant No. 0552885. Additional funding and support were generously contributed by Conacyt, Turbomachinery Research Consortium, Honeywell Turbo Technologies, NASA GRC, TRC, Capstone Turbine Corp, Haas, Unist, MA Ford, Cideteq, Comimsa, and Agilent Technologies.

\section{References}

[1] Chittipolu, S., Micromachining of 316L Stainless Steel, Thesis, Texas A\&M University, 2008.

[2] Hung N.P., Chittipolu S., Kajaria S., Makarenko M., Purdy A., Bickston L., and Williamson D., "Micromachining of 316L Stainless Steel," Micro/Nano Manufacturing Conference, SME, Framingham, Massachusetts, April 2008.

[3] Hung N.P., Sundarram S., Vasiraju V., and Powers M., "High Frequency Electrochemical Micromachining," SME Micro/Nano Manufacturing Conference, Minneapolis, Minnesota, April 2009.

[4] Kajaria, S., Modeling of Tool Life and Micromist flow for Effective Micromachining of 316L Stainless Steel, Thesis, Texas A\&M University, 2009.

[5] Ozkeskin F., Sundarram S., Powers M., Manríquez J., Godínez L., Strohm G., Allison, S., and Hung N.P., "Automatic Control of High Frequency Electrochemical Microsystem," 54th International Instrumentation Symposium, Pensacola, Florida, May 2008. 
[6] Ozkeskin, F.M., Feedback Controlled High Frequency Electrochemical Micromachining, Thesis, Texas A\&M University, 2008.

[7] San Andrés, L., Kim, T.H., Ryu, K., Chirathadam, T. A., Hagen, K., Martinez, A., Rice, B., Niedbalski, N., Hung, W. and Johnson, M., Gas Bearing Technology for Oil-Free Microturbomachinery - Research Experience for Undergraduate (REU) Program at Texas A\&M University, Proc. ASME Turbo Expo 2009, Paper No. GT2009-59920, Orlando, Florida, June 2009.

[8] San Andrés, L., Camero J., Muller S. Chirathadam T., and Ryu K., Measurements of Drag Torque, Lift Off Speed, and Structural Parameters in a First Generation Floating Gas Foil Bearing, Proc. $8^{\text {th }}$ IFToMM Inter. Conf. on Rotodynamics, Seoul, Korea, September 2010.

[9] Sundarram S., Powers M., Ozkeskin F., Manríquez J., Godínez L., and Hung N.P., "Electrochemical Micromachining of $\mathrm{Cu}$ 2Be Alloy and 316L Stainless Steel," SME, Micro/Nano Manufacturing Conference, Massachusetts, April 2008.

[10] Sundarram, S.S., Development of Electrochemical Micromachining, Thesis, Texas A\&M University, 2008. 